\title{
Knowledge, Attitude and Practices of Pharmaceutical Waste Disposal in Community Pharmacies of Karachi
}

\author{
Amna Khan ${ }^{1}$, Nazish Jaffar*1, Sadaf Razzak ${ }^{1}$, Faiza Zeeshan ${ }^{1}$, \\ Asma Shabbir ${ }^{1}$ and Syed Muhammad Ishaque ${ }^{2}$
}

\begin{abstract}
Objectives: The aim of the study was to assess the knowledge of community pharmacies about recommended methods of drug disposal and hazardous effects of improper disposal of pharmaceutical waste and to determine the attitude as well as practice of community pharmacies about the proper disposal of pharmaceutical waste. Methods: A cross-sectional study was performed with 139 community pharmacies in Karachi, Pakistan by using non-probability convenient sampling technique. Predesigned structured questionnaire was distributed to different community pharmacies in Karachi and filled questionnaires were collected after one day. Data was analyzed using SPSS 22.0

Results: About 65 (46.8\%) of the participants reported to have a system for regularly removing the expired or unused drugs by returning them to contractors/distributors. More than half $86(61.9 \%)$ of the participants disposed of solid, liquid, semi-solid, controlled, and p-listed drugs in the rubbish bin. Approximately half of the participants believed that standard method for disposal of solid, liquid, semi-solid, controlled, and p-listed drugs is by flushing them down the toilet/sink.

Conclusion: Our study showed that knowledge and practices of community pharmacies regarding disposal of unused and expired medicines were not satisfactory. However, most of the participants were well aware of the harmful effects caused by improper disposal of pharmaceutical waste on environment and showed positive attitude towards learning safe methods of management and disposal of unused and expired drugs.
\end{abstract}

Key words: Community pharmacy, pharmacists, disposal, environment, Karachi

How to cite this article: Khan A, Jaffar N, Razzak S, Zeeshan F, Shabbir A, Ishaque SM. Knowledge, attitude and practices of pharmaceutical waste disposal in community pharmacies of Karachi. Ann Jinnah Sindh Med Uni 2020; 6(2):54-59

DOI: https://doi.org/10.46663/ajsmu.v6i2.54-59

\section{INTRODUCTION}

Environmental pollution is one of the biggest threats which the world is facing today. One of the major contributing factors is improper disposal of unused and expired medications which is causing water as well as land pollution. It is adversely affecting the environment, health of human beings and animals ${ }^{1,2}$. Different types of drug preparations include solid (tablets), liquid (syrups) and semi-solid (ointments) formulations $^{3,4}$. Drugs such as opioids, stimulants, hallucinogens, anabolic steroids capable of causing addiction and substance use disorder are classified as control drugs ${ }^{5,6}$. P-listed drugs such as warfarin, nicotine

1 Department of Pathology, Sindh Medical College, Jinnah Sindh Medical University, Karachi, Pakistan

2 Assistant Professor, Department of Pathology, Bolan University of Medical \& Health Sciences, Quetta, Pakistan Correspondence: Dr Nazish Jaffar*, Assistant Professor, Department of Pathology, Sindh Medical College, Jinnah Sindh Medical University, Karachi, Pakistan

Email: drnazishamin@gmail.com patches, and physostigmine are classified as acutely toxic drugs that can cause death and irreversible illness even at low doses ${ }^{7}$.

In many countries, the recommended method to dispose of unused and expired medicines is to return them to pharmacies. However, it will be beneficial only if pharmacists also dispose them in a proper manner, ${ }^{8,9}$. Improper disposal of medicines produces a lot of harmful effects in man and animals which may include accumulation of pharmaceutical residues in body after drinking contaminated water, poisoning in children and adults, antibiotic resistance, production of deadly mutant bacterial strains, substance use disorders, infertility in fishes, which will ultimately lead to disturbance in food chain etc ${ }^{10,11}$.

The common methods of disposal of expired medicine are reported to be throwing them either into toilet, sink, or garbage ${ }^{12,13}$. Different studies reported wellestablished policies and programmes in developed countries for proper disposal and management of 
pharmaceutical waste, whereas, developing countries lack such programmes ${ }^{8,9}$. A study in Ethiopia reported flushing medicines down the toilet/sink as the common disposal practice ${ }^{14}$.

According to a study in India, most of the leftover drugs belonging to different dosage forms were returned to the distributor, whereas one third of the pharmacists did not know the correct method to dispose of drugs ${ }^{15}$. Moreover, only a few studies in Pakistan and Afghanistan reported the practices of general public regarding pharmaceutical waste management ${ }^{16,17}$.

According to the World Health Organization (WHO), a pharmacist is a caregiver, the decision maker, communicator, manager, lifelong learner, teacher, and leader ${ }^{18}$. To the best of our knowledge, no study has been conducted until now in Karachi considering the practices of community pharmacies regarding drug disposal. Therefore, the present study was aimed to assess the knowledge of community pharmacies about hazardous effects of improper disposal of pharmaceutical waste and to determine the attitude as well as practices of community pharmacies about the proper disposal of pharmaceutical waste.

\section{METHODOLOGY}

A descriptive cross-sectional study was conducted during June, 2020 with a total of 139 community pharmacies in Karachi by using non-probability convenient sampling technique. Ethical approval was obtained from Institutional Review Board of Jinnah Sindh Medical University (JSMU/IRB/2020/-301) and written informed consent was acquired before data collection. All consenting pharmacists/pharmacy technicians from Karachi practicing for the minimum duration of at least three years and aged more than 25 years were enrolled in our study whereas, all nonconsenting pharmacists/pharmacy technicians and participants with ages less than 25 years were excluded. Data was collected by distributing a predesigned structured questionnaire to different community pharmacies in Karachi and filled questionnaires were collected after one day. The questionnaire was prepared after extensive literature review from Google Scholar and comprised four parts. The first part included sociodemographic data (age, gender, education, number of years for which he/she is practicing as pharmacist). Second part comprised their knowledge and attitude about the recommended methods of drug disposal. Third section inquired about hazards of improper methods of drug disposal. The fourth part included current practices of community pharmacies regarding disposal of unused and expired medication.
Sample size was obtained using Open EPI software (www.openepi.com/Menu/OE_Menu.htm ) Using confidence interval of $95 \%(\mathrm{z}$ score $=1.96) 90 \%{ }^{15}$ as prevalence from previous study and 5\% allowable error of known prevalence, sample size obtained was $n=139$.

Data was analyzed using SPSS version 22.0. Descriptive statistics were used to determine mean and standard deviation for numerical variables. Categorical variables were expressed in frequency and percentages.

\section{RESULTS}

A total of 139 pharmacists/pharmacy technicians practicing in Karachi were included in our study. The majority 138 (99.3\%) of the participants were males aged between 25-35 year. Mean age with standard deviation was 36.0 48.7 . Most 93 (66.9\%) of the respondents were practicing for less than 10 years. More than half $82(58.9 \%)$ of the participants were neither graduates nor diploma holders. Less than half $68(48.9 \%)$ of the participants were taught different disposal techniques during graduation/diploma whereas, approximately one-third of the participants felt the need to learn more about safe and environment friendly techniques for pharmaceutical waste disposal. (Table 1-2)

The frequency of enquiry from customers about advice on drug disposal was received in the frequency of never $50(36.0 \%)$, sometimes $72(51.8 \%)$, and always 17 (12.2\%). (Table 1) More than half 98 (70.5\%) of the participants took help of pharmaceutical sales representatives to get updated information for disposal of unused or expired medications. (Figure 1)

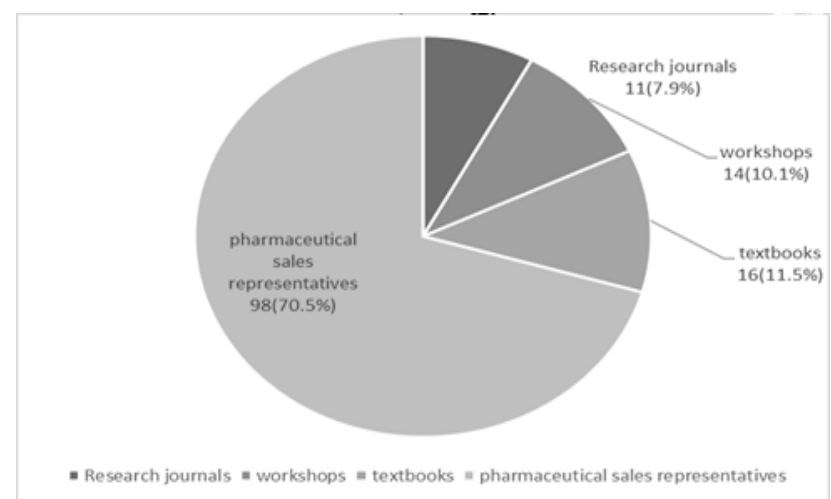

Figure 1: Different Sources of Updated Information for Participants Regarding Disposal of Pharmaceutical Waste N (\%)

However, knowledge about recommended method of disposal of different dosage forms was inadequate as approximately half of the participants believed that standard method for disposal of solid, liquid, semisolid, controlled and p-listed drugs is by flushing them down the toilet/sink. More than half of the participants 
are aware of drug take back system whereas approximately one-third reported that they do not take back unused or expired medicines from the customers. (Table 1)

Knowledge of participants regarding environmental impact of improper pharmaceutical waste disposal was satisfactory. Many 115 (82.7\%) participants admitted that improper drug disposal is linked to environmental pollution and contamination of drinking water. Furthermore, $101(72.7 \%)$ reported that it also causes antibiotic resistance. Some of them $79(56.8 \%)$ reported incineration as unfavorable method for pharmaceutical waste disposal. (Figure 2)

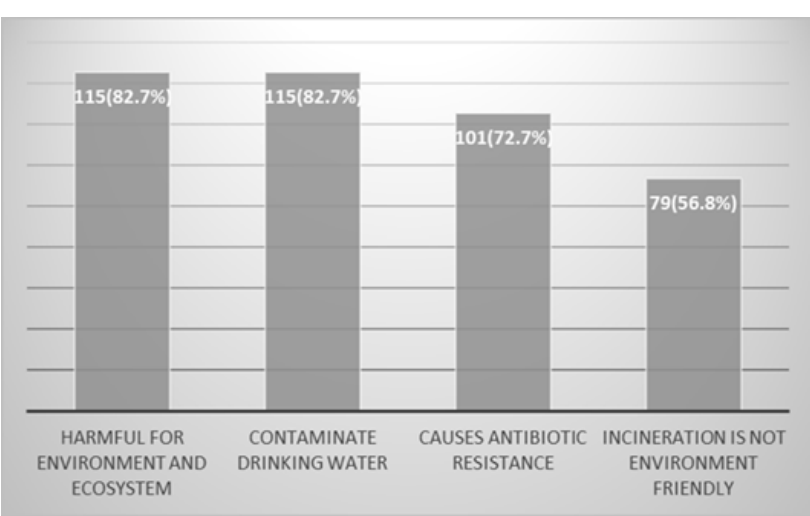

Figure 2: Knowledge of Participants Regarding Environmental Impact of Improper Pharmaceutical Waste Disposal N (\%)

More than one-third of the participants asked for a proper system to regularly remove the expired or unused drugs by returning them to contractors/ distributors. However, approximately half of the participants practiced disposing of solid, liquid, semisolid, controlled and p-listed drugs in the rubbish bin. (Table 2, Figure 3) More than half of the participants reported educating general public as the best way to minimize pharmaceutical waste. (Table 1)

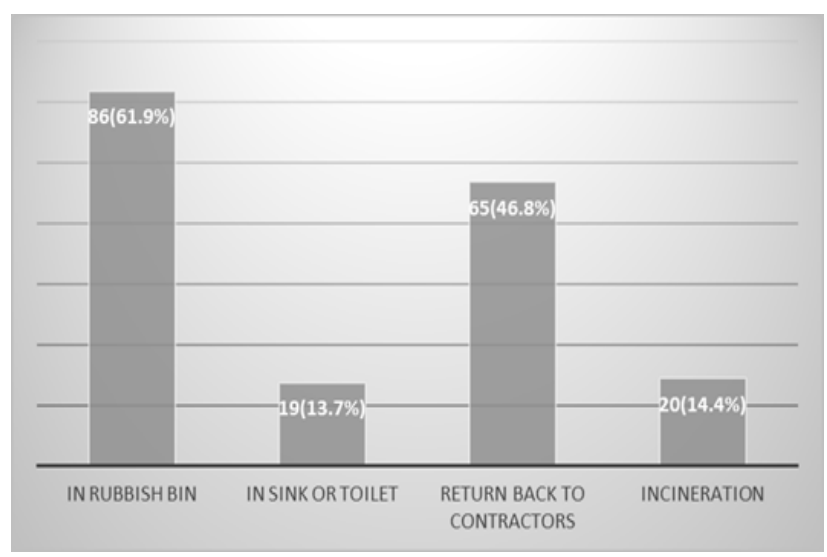

Figure 3: Different Methods of Disposal for Unused and Expired Medicines Practiced by Community Pharmacies N (\%)
Table 1: Sociodemographic Data and Knowledge of Pharmacists/ Pharmacy Technicians About Recommended Methods of Drug Disposal:

\begin{tabular}{|c|c|c|}
\hline Variables: & $\mathrm{N}(\%)$ & Mean \pm SD \\
\hline $\begin{array}{l}\text { Age group: } \\
25-35 \\
36-45 \\
46-55 \\
56-65 \\
\end{array}$ & \begin{tabular}{|c|}
$75(54.0)$ \\
$44(31.7)$ \\
$17(12.2)$ \\
$3(2.2)$
\end{tabular} & $(36.0 \pm 8.7)$ \\
\hline $\begin{array}{ll}\text { Gender: } & \\
& \text { Male } \\
& \text { Female } \\
\end{array}$ & $\begin{array}{c}138(99.3) \\
1(0.7) \\
\end{array}$ & $\begin{array}{c}\text { M: F ratio } \\
(138: 1)\end{array}$ \\
\hline $\begin{array}{l}\text { Number of practicing years: } \\
\text { Less than 10 years } \\
11-20 \text { years } \\
21-30 \text { years } \\
31-40 \text { years } \\
\text { Over 40 years } \\
\end{array}$ & \begin{tabular}{|c|}
$93(66.9)$ \\
$37(26.6)$ \\
$5(3.6)$ \\
$3(2.2)$ \\
$1(0.7)$ \\
\end{tabular} & $(10.4 \pm 7.3)$ \\
\hline $\begin{array}{l}\text { Qualification: } \\
\text { Graduation in pharmacy } \\
. \\
\text { Diploma in pharmacy technician } \\
\text { Others }\end{array}$ & $\begin{array}{l}20(14.4) \\
37(26.6) \\
82(58.9) \\
\end{array}$ & \\
\hline $\begin{array}{l}\text { Medicine disposal techniques were taught } \\
\text { during graduation/diploma: } \\
\text { Did customer ever enquire about advice } \\
\text { on drug disposal: } \\
\text {. Never } \\
\text { Sometimes } \\
\text { Always } \\
\end{array}$ & \begin{tabular}{|l|}
$68(48.9)$ \\
\\
$50(36.0)$ \\
$72(51.8)$ \\
$17(12.2)$ \\
\end{tabular} & \\
\hline $\begin{array}{l}\text { Customer returned unused or expired } \\
\text { medication: } \\
\text { We do not take back unused or expired } \\
\text { medications: } \\
\text { I know about drug take back system: } \\
\text { Recommended method to dispose of } \\
\text { solid dosage forms: } \\
\text { By disposal in landfills } \\
\text { By incineration } \\
\text { By flushing the medicine } \\
\text { down the toilet/sink } \\
\text { Take back system } \\
\text { Don't know }\end{array}$ & \begin{tabular}{|l|}
$70(50.4)$ \\
$69(49.6)$ \\
$87(62.6)$ \\
\\
$32(23.0)$ \\
$12(8.6)$ \\
$70(50.4)$ \\
$1(0.7)$ \\
$24(17.3)$
\end{tabular} & \\
\hline $\begin{array}{l}\text { Recommended method to dispose of } \\
\text { liquid dosage forms: } \\
\text { By disposal in landfills } \\
\text { By incineration } \\
\text { By flushing the medicine } \\
\text { down the toilet/sink } \\
\text { Take back system } \\
\text { Don't know }\end{array}$ & \begin{tabular}{|}
$32(23.0)$ \\
$7(5.0)$ \\
$67(48.2)$ \\
$1(0.7)$ \\
$32(23.0)$
\end{tabular} & \\
\hline 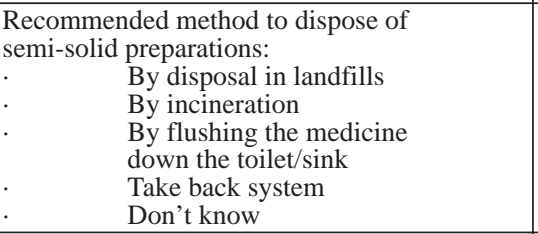 & \begin{tabular}{|c|}
$29(20.9)$ \\
$9(6.5)$ \\
$63(45.3)$ \\
\\
$1(0.7)$ \\
$37(26.6)$ \\
\end{tabular} & \\
\hline $\begin{array}{l}\text { Recommended method to dispose of } \\
\text { controlled drug preparations: } \\
\text { By disposal in landfills } \\
\text { By incineration } \\
\text { By flushing the medicine } \\
\text { down the toilet/sink } \\
\text { Take back system } \\
\text { Don't know }\end{array}$ & $\begin{array}{c}31(22.3) \\
11(7.9) \\
63(45.3) \\
1(0.7) \\
33(23.7)\end{array}$ & \\
\hline $\begin{array}{l}\text { Recommended method to dispose of } \\
\text { p-listed drugs: } \\
\text { By disposal in landfills } \\
\text { By incineration } \\
\text { By flushing the medicine } \\
\text { down the toilet/sink } \\
\text { Take back system } \\
\text { Don't know } \\
\end{array}$ & \begin{tabular}{|c|}
$33(23.7)$ \\
$11(7.9)$ \\
$56(40.3)$ \\
$1(0.7)$ \\
$38(27.3)$ \\
\end{tabular} & \\
\hline $\begin{array}{ll}\text { Best way to minimize pharmaceutical waste: } \\
\text { By drug take back system } \\
. & \text { By donation } \\
. & \text { By educating general public } \\
& \text { First sell drugs nearing expiry dates }\end{array}$ & $\begin{array}{l}17(12.2) \\
19(13.7) \\
74(53.2) \\
29(20.9)\end{array}$ & \\
\hline
\end{tabular}


Table 2: Practices and Attitude of Pharmacists/Pharmacy

Technicians Regarding Pharmaceutical Waste Disposal:

\begin{tabular}{|c|c|}
\hline Variables: & $\mathrm{N}(\%)$ \\
\hline $\begin{array}{l}\text { 1-How would you dispose of solid } \\
\text { dosage forms? } \\
\text { In the rubbish bin } \\
\text { In the sink/toilet } \\
\text { By incineration } \\
\text { Send back to pharmaceutical } \\
\text { distributors or contractors }\end{array}$ & $\begin{array}{l}79(56.8) \\
18(12.9 \\
12(8.6) \\
30(21.6)\end{array}$ \\
\hline $\begin{array}{l}\text { 2-How would you dispose of liquid } \\
\text { dosage forms? } \\
\text { In the rubbish bin } \\
\text { In the sink/toilet } \\
\text { By incineration } \\
\text { Send back to pharmaceutical } \\
\text { distributors or contractors }\end{array}$ & $\begin{array}{l}65(46.8) \\
6(4.3) \\
13(9.4) \\
55(39.6)\end{array}$ \\
\hline $\begin{array}{l}\text { 3-How would you dispose of semi-solid } \\
\text { preparations? } \\
\text { In the rubbish bin } \\
\text { In the sink/toilet } \\
\text { By incineration } \\
\text { Send back to pharmaceutical } \\
\text { distributors or contractors }\end{array}$ & $\begin{array}{l}62(44.6) \\
8(5.8) \\
8(5.8) \\
61(43.9)\end{array}$ \\
\hline $\begin{array}{l}\text { 4-How would you dispose of controlled } \\
\text { drug preparations? } \\
\text { In the rubbish bin } \\
\text { In the sink/toilet } \\
\text { By incineration } \\
\text { Send back to pharmaceutical } \\
\text { distributors or contractors }\end{array}$ & $\begin{array}{l}61(43.9) \\
5(3.6) \\
10(7.2) \\
63(45.3)\end{array}$ \\
\hline $\begin{array}{l}\text { 5-How would you dispose of P-listed drugs? } \\
\text { In the rubbish bin } \\
\text { In the sink/toilet } \\
\text { By incineration } \\
\text { Send back to pharmaceutical } \\
\text { distributors or contractors }\end{array}$ & $\begin{array}{l}66(47.5) \\
4(2.9) \\
10(7.2) \\
59(42.4)\end{array}$ \\
\hline $\begin{array}{l}\text { 6-I would like to learn more about safe } \\
\text { and environment friendly techniques for } \\
\text { pharmaceutical waste disposal. }\end{array}$ & $50(36.0)$ \\
\hline
\end{tabular}

\section{DISCUSSION}

Unused and expired medicines should be disposed of properly to avoid accumulation of toxic and harmful residues in the environment. As they are potentially harmful substances, improper disposal could cause toxicity in human beings and animals ${ }^{19,20}$. In Pakistan, there is limited literature on methods used by community pharmacies for management of pharmaceutical waste. The present study was designed to assess the knowledge of community pharmacies about hazardous effects of improper disposal of pharmaceutical waste and to determine the attitude as well as practice of community pharmacies about the proper disposal of pharmaceutical waste.

Results of our study showed that most of the community pharmacies do not have proper system for disposal of unused and expired medications and there is lack of knowledge about proper pharmaceutical waste disposal among pharmacists/pharmacy technicians. The best way to dispose of most types of old, unused, or expired medicines both prescribed and over the counter is to drop off the medicine at a drug take back site, location, or programme immediately. If it is on the FDA flush list, it should be immediately flushed. If it is not on flush list then it ought to be removed from original container and be mixed with any undesirable substance such as coffee grounds or kitty litter and placed in a sealable bag, empty can or other container to prevent any leaking of the drug. Controlled drugs such as opioids should be flushed to reduce unintentional or illegal use. Studies reported that environmental effects caused by flushing of FDA approved medicines are insignificant $^{21}$.

In the present study, majority of the pharmacists/ pharmacy technicians believed that flushing all medicines down the toilet/sink (whether solid, liquid, semi-solid or controlled dosage forms and p-listed drugs) is the recommended method of disposal. This finding confirmed an inadequate knowledge of participants regarding recommended methods of drug disposal. However, if drug take back programmes are not available, some medications listed by FDA can be disposed of in toilet/sink ${ }^{22}$.

Most of the respondents were not taught about the recommended disposal techniques during graduation or diploma courses. Pharmaceutical sales representatives were considered as the guiding source for disposal of unused and expired medications followed by textbooks, workshops, and research journals. This is in contrast to a study conducted in India which showed workshops as the most common source of updated information regarding disposal of pharmaceutical waste ${ }^{15}$.

Pharmaceutical residues enter the environment through primary route which is unintentional and unavoidable by means of excretion and bathing and secondary route i.e. disposal of pharmaceutical waste into trash and sewerage. Humans as well as aquatic animals are exposed to these trace residues as even modern water treatment plants do not remove them completely 8,14 . Non-steroidal anti-inflammatory drugs, hormones and antibiotics are the drugs that adversely affect the ecosystem ${ }^{16}$. Studies have reported that flushing of antibiotics down the toilet/sink causes mutations in different bacterial strains ultimately leading to antibiotic resistance. Improper disposal of oral contraceptive pills containing estrogen cause infertility in fish leading to disturbances in food chain. Controlled drugs such as opioids, stimulants, hallucinogens, anabolic steroids disposed of in rubbish bin may lead to substance use disorders $8,10,11,20$. Most of the participants in our study also agreed that improper pharmaceutical waste management is harmful for our environment and ecosystem and they would like to learn more about safe and environment friendly techniques for disposal of unwanted medicines. Only some of the participants 
agreed that incineration is not an eco-friendly way to dispose of unused and expired medications. Studies showed that incineration is the most environmentally friendly method of pharmaceutical waste disposal however, it is prohibited in case of inhalers ${ }^{14,21}$.

Very few pharmacists in our study expressed drug take back programme as the best way to minimize harmful effects of pharmaceutical waste on environment and ecosystem. However, majority of respondents were of the opinion that educating general public is the best possible solution to avoid pharmaceutical waste. Our findings are similar to study conducted in Ethiopia where only $1 \%$ of the respondents believed that returning unused and expired drugs to the pharmacies would be the best way to minimize pharmaceutical waste $^{8}$. The purpose of drug take back programme is to help recipients in properly disposing of their prescribed and over the counter medications in order to avoid addition of harmful pharmaceutical residues in the environment. People should not buy medicines in excess and unused medications should be returned to pharmacies immediately or should be donated to hospital emergency departments.

Most of the pharmacists in our study reported disposal of different types of drugs in rubbish bin which is similar to practices of general public in Pakistan ${ }^{16}$ and India ${ }^{23,24}$ whereas, controlled drug preparations were sent back to pharmaceutical distributors or contractors. It might be because only some of the respondents had ever received proper training on pharmaceutical waste management. In Nepal, most of the unused and expired medicines were disposed of via municipal garbage truck whereas, some of the participants also discarded them into garbage dumps and informal waste collectors ${ }^{25}$.

Our study also observed that most of the community pharmacies did not take back unused and expired drugs from the customers probably because they were unaware about drug take back system. However, community pharmacies following drug take back system reported that they return unused or expired medications to the distributors or contractors six months before expiry therefore, medicines brought by customers with expiry date of less than six months were not accepted.

Our study findings emphasized the need for development of programmes and policies to ensure collection of unused and expired medicines from general public and community pharmacies and then subsequently disposing them in an environmentally friendly manner.

\section{LIMITATIONS:}

Some of the participants might not have reported actual practices due to the fear of being exposed for unprofessional conduct. Findings of our research cannot be generalized as it is a single center study.

\section{CONCLUSION}

We conclude that knowledge and practices of community pharmacies regarding disposal of unused and expired medicines is not satisfactory. However, most of the participants are well aware of the harmful effects caused by improper disposal of pharmaceutical waste on environment and showed positive attitude towards learning safe methods in order to properly dispose of unused and expired medications. Proper system is required for collection of old, unused, expired medicines with subsequent disposal according to guidelines.

Funding: None to declare

Conflict of interest: None to declare

Authors' contribution: AK conceived the idea, did statistics and manuscript writing. NJ did critical review and editing. SR did critical review. FZ did literature review. SMI did final approval.

\section{References}

1. Kristina SA, Wiedyaningsih C, Cahyadi A, Ridwan BA. A Survey on Medicine Disposal Practice among Households in Yogyakarta. Asian J Pharm. 2018;12(3):.S955-S959. doi.org/10.22377/ajp. v12i03.2633

2. Bashatah A, Wajid S. Knowledge and Disposal Practice of Leftover and Expired Medicine: A Cross-Sectional Study from Nursing and Pharmacy Students' Perspectives. Int J Environ Res. Public Health. 2020; 17(6):2068.doi.org/10.3390/ijerph 17062068

3. What are the Different Forms of Drug Formulation? Cognibrain.com. [Internet] 2020. https:// www. cognibrain.com/pharmaceutical-formulations/(Accessed on $5 / 22 / 2020)$

4. Nardi-Ricart A, Linares MJ, Villca-Pozo F, PérezLozano P, Suñé-Negre JM, Bachs-deMiquel L, et al. A new design for the review and appraisal of semi-solid dosage forms: Semi-solid Control Diagram (SSCD). PloS one. 2018;13(9): e0201643. doi.org/ 10.1371/ journal.pone.0201643

5. Controlled drugs: safe use and management. National Institute for health and care excellence.[Internet] 2016. https://www.nice.org.uk/guidance/ng46/evidence/fullguideline-pdf-2427186353. (Accessed on 5/23/2020)

6. Controlled drug substance. (n.d.) McGraw-Hill Concise Dictionary of Modern Medicine. (2002). [Internet] 2002. https://medical-dictionary. thefreedictionary. com/controlled+drug+substance. (Accessed on $5 / 23 / 2020$ ) 
7. Dubey R, Upmanyu N. Role of pharmacist in pharmaceutical waste management. World. 2017;6(2):1-3.

8. Ayele Y, Mamu M. Assessment of knowledge, attitude and practice towards disposal of unused and expired pharmaceuticals among community in Harar city, Eastern Ethiopia. J Pharm Policy Pract 2018;11(1):27. doi. org/ 10.1186/s40545-018-0155-9

9. Lucca JM, Alshayban D, Alsulaiman D. Storage and disposal practice of unused medication among the Saudi families: An endorsement for best practice. Imam J Appl Sci. 2019 Jan 1;4(1):1-6. DOI: 10.4103/ijas. ijas_ 21_18

10. Yu X, Hu X, Li S, Zhang M, Wang J. Attitudes and practice regarding disposal for unwanted medications among young adults and elderly people in China from an ecopharmacovigilance perspective. Int $\mathbf{J}$ Environ Res Public Health. 2019;16(8): 1463.doi.org/ 10.3390/ ijerph16081463

11. Michael I, Ogbonna B, Sunday N, Anetoh M, Matthew O. Assessment of disposal practices of expired and unused medications among community pharmacies in Anambra State southeast Nigeria: a mixed study design. J Pharm Policy Pract. 2019 Dec;12(1):12. doi.org/10.1186/s40545-019-0174-1

12. Naveen A, Suguna A, Basineni M. A study on unused and expired drug disposal practices: knowledge and behavioural patterns among the rural population. Int $\mathbf{J}$ Sci Res 2019 Jun 17;8(6).

13. Shaaban H, Alghamdi H, Alhamed N, Alziadi A, Mostafa A. Environmental contamination by pharmaceutical waste: assessing patterns of disposing unwanted medications and investigating the factors influencing personal disposal choices. J Pharmacol Pharm Res. 2018;1(1):003.

14. Kassahun H, Tesfaye D. Disposal Practices of Unused Medications Among Patients in Public Health Centers of Dessie Town, Northeast Ethiopia: A Cross Sectional Survey. Integr Pharm Res Pract. 2020; 9:65. doi. org/ 10.2147\%2FIPRP.S243069

15. Aditya S, Rattan A. Minimizing pharmaceutical waste: the role of the pharmacist. J Young Pharm 2014;6(3):1419. DOI: $10.5530 /$ jyp.2014.3.3
16. Shahid R, Ahmed A, Islam S, Anjum F, Anwar O, Ghayas S. Concept Of Drug Disposal Among Karachiites. In14th International Conference on 2016 Mar 14 (p. 479).

17. Bashaar M, Thawani V, Hassali MA, Saleem F. Disposal practices of unused and expired pharmaceuticals among general public in Kabul. BMC public health. 2017; 17(1):45. doi.org/10.1186/s12889-016-3975-z

18. Hallit S, Hajj A, Sacre H, Zeenny RM, Akel M, Sili G et al. Emphasizing the Role of Pharmacist as a Researcher: The Lebanese Order of Pharmacists' Perspective. J Res Pharm Pract 2019;8(4):229..doi: 10. 4103/jrpp.JRPP_19_7

19. Zorpas AA, Dimitriou M, Voukkali I. Disposal of household pharmaceuticals in insular communities: social attitude, behaviour evaluation and prevention activities. Environ Sci Pollut Res Int. 2018;25(27):2672535.doi.org/10.1007/s11356-017-9551-y

20. Albaroodi KA. Pharmacists' Knowledge Regarding Drug Disposal in Karbala. Pharmacy. 2019;7(2): 57. doi.org/10.3390/pharmacy 7020057

21. Where and How to Dispose of Unused Medicines. U.S. Food and Drug Administration. [Internet] 2020. https:// www.fda.gov/consumers/consumer-updates/where-andhow-dispose-unused-medicines. (Accessed on 5/12/2020)

22. Aquino S, Antonio Spina G, Leitão Zajac MA, Luiz Lopes E. Reverse Logistics of Postconsumer Medicines: The Roles and Knowledge of Pharmacists in the Municipality of São Paulo, Brazil. Sustainability. 2018;10(11):4134. doi.org/10.3390/su10114134

23. Manocha S, Suranagi UD, Sah RK, Chandane RD, Kulhare S, Goyal N, et al. Current Disposal Practices of Unused and Expired Medicines Among General Public in Delhi and National Capital Region, India. Current Drug Safety. 2020;15(1):13-9. doi. org/ 10.2174/ 1574886314666191008095344

24. Shwetha N, Jha A. Knowledge and Awareness Regarding Safe Drug Disposal System among General Population of India. J Pharmacovigil. 2018;6(2):256. DOI: 10.4172/ 2329-6887.1000256

25. Paudel E, Choi E, Shrestha N. Pharmaceutical waste management in private pharmacies of Kaski District, Nepal Int J Innov Sci Res Technol. 2019:2456-165 